\title{
Occupational exposure and risk of breast cancer (Review)
}

\author{
CONCETTINA FENGA \\ Department of Biomedical and Dental Sciences and Morphofunctional Imaging, Occupational Medicine \\ Section, ‘Policlinico G. Martino’ Hospital, University of Messina, I-98125 Messina, Italy
}

Received December 10, 2015; Accepted December 24, 2015

DOI: $10.3892 /$ br.2016.575

\begin{abstract}
Breast cancer is a multifactorial disease and the most commonly diagnosed cancer in women. Traditional risk factors for breast cancer include reproductive status, genetic mutations, family history and lifestyle. However, increasing evidence has identified an association between breast cancer and occupational factors, including environmental stimuli. Epidemiological and experimental studies demonstrated that ionizing and non-ionizing radiation exposure, night-shift work, pesticides, polycyclic aromatic hydrocarbons and metals are defined environmental factors for breast cancer, particularly at young ages. However, the mechanisms by which occupational factors can promote breast cancer initiation and progression remains to be elucidated. Furthermore, the evaluation of occupational factors for breast cancer, particularly in the workplace, also remains to be explained. The present review summarizes the occupational risk factors and the associated mechanisms involved in breast cancer development, in order to highlight new environmental exposures that could be correlated to breast cancer and to provide new insights for breast cancer prevention in the occupational settings. Furthermore, this review suggests that there is a requirement to include, through multidisciplinary approaches, different occupational exposure risks among those associated with breast cancer development. Finally, the design
\end{abstract}

Correspondence to: Professor Concettina Fenga, Department of Biomedical and Dental Sciences and Morphofunctional Imaging, Occupational Medicine Section, 'Policlinico G. Martino' Hospital, University of Messina, Via Consolare Valeria 1, I-98125 Messina, Italy

E-mail: cfenga@unime.it

Abbreviations: $\mathrm{PAH}$, polycyclic aromatic hydrocarbon; EMF, electromagnetic fields; IARC, International Agency for Research on Cancer; EDC, endocrine-disrupting chemical; UNSCEAR, United Nations Scientific Committee on the Effects of Atomic Radiation; $\mathrm{PCB}$, polychlorinated biphenyl; OCP, organochlorines pesticide; DDE, dichlorodiphenyldichlroethylene; BaP, benzo[a]pyrene; OP, organophosphate; DDT, dichlorodiphenyltrichloroethane; AhR, aryl hydrocarbon receptor; $\mathrm{AHH}$, aryl hydrocarbon hydroxylase; ER $\alpha$, estrogen receptor $\alpha$; SNP, single-nucleotide polymorphism; Cd, cadmium; $\mathrm{Pb}$, lead; $\mathrm{Cu}$, copper; $\mathrm{Cr}$, chromium; $\mathrm{Zn}$, zinc; $\mathrm{Hg}$, mercury

Key words: breast cancer, occupational exposure, pesticides, metals, night-shift work, ionising radiation, benzene of new epigenetic biomarkers may be useful to identify the workers that are more susceptible to develop breast cancer.

\section{Contents}

1. Introduction

2. Methods

3. Environmental exposure

4. Conclusions

\section{Introduction}

Breast cancer is the most commonly diagnosed cancer in women and the second worldwide cause of fatality among female patients, following lung cancer (1).

Although diagnostic, therapeutic and preventive improvements have been reached in the past, the incidence of breast cancer is still increasing in all countries, particularly those undergoing rapid changes in human development $(2,3)$. Nearly $12 \%$ of women will experience invasive breast cancer in their lifetime, which equates to $>20$ million cases (4).

The lifetime risk of fatality from breast cancer is $\sim 3.4 \%$. The international incidence of female breast cancer varies markedly, being highest in the United States, Australia, New Zealand, Western and Northern Europe (incidence $>80 / 100,000$ ); intermediate in Southern and Eastern Europe and South America, and lowest in Asia and among African women living in sub-Saharan Africa (incidence $\leq 30 / 100,000)(5,6)$.

The wide range of female breast cancer mortality rates is less marked compared to variations in incidence, due to improved survival in high-income countries compared to lowand-middle-income countries (3).

A number of accepted risk factors for breast cancer include reproductive status, genetic mutations and family history; however, lifestyle, environmental or occupational features of breast cancer are not completely verified (7-9).

The International Agency for Research on Cancer (IARC) assessed the carcinogenicity of numerous substances, which could definitely or possibly produce breast cancer $(10,11)$. According to the IARC classification (11), there are no agents with sufficient evidence in humans that can be classified as 'carcinogenic to humans' (group 1) to the human breast, which could be considered work related (6).

Exposure to night-shift work represents the most significant occupational risk associated with breast cancer and it has been 
Table I. Search terms strategy for PubMed/Scholar.

\begin{tabular}{ll}
\hline Strategy & \multicolumn{1}{c}{ Search terms } \\
\hline 1) & Breast cancer, mammary cancer, breast neoplasm, breast OR mammary tumor \\
2) & Occupation, occupational, work-related, workers, environmental, pollutants, occupational exposure OR risk \\
$3)$ & Ionising radiation, non-ionising radiation, electromagnetic fields \\
$4)$ & Endocrinedisruptors,pesticides,organochlorine,DDT,organophosphates, carbamates,pyrethroids, disulfiram, \\
5) & Carathion, malathion \\
6) & 1,2-Dichloroethane, 1,2-dichloropropane \\
7) & Night work, shift work, night-shift work \\
\hline
\end{tabular}

PAH, polycyclic aromatic hydrocarbon; DDT, dichlorodiphenyltrichloroethane.

classified as a carcinogen by the IARC (10). Several studies among nurses have indicated that this population has a higher risk to develop breast cancer compared to the general female population, showing a close association between occupation and cancer development (12-14).

The IARC also established a strong association that exposure to ionizing radiation can increase the risk of breast cancer (15). Additionally, non-ionizing radiation, mainly electromagnetic fields (EMF) have been implicated in the pathogenesis of breast cancer in women and in men, suggesting an association between breast cancer and EMF that requires further evaluation (16).

Similarly, chemical substances such as ethylene oxide, polycyclic aromatic hydrocarbons (PAHs), perfluorooctanoic acid and different pesticides are investigated as carcinogenic factors for breast cancer in occupational settings $(17,18)$. All these substances, known as endocrine-disrupting chemicals (EDCs), can alter endocrine processes and disrupt normal mammary tissue development, thus leading to adverse lifetime consequences (19). According to several studies, it is important to evaluate not only the time of exposure, mainly when the mammary gland is less differentiated and more sensitive, but also the effects which EDCs could produce at low doses of exposure $(20,21)$.

Severe inhibitions of mammary development have only been observed in rodents at high EDC levels of exposure (19). These elevated doses may not be reached in humans except in rare cases of high occupational or non-occupational accidental exposures (such as pollution). The exact mechanisms for these changes remain to be elucidated; however, it was recently established that EDCs can alter the epigenome in cancers (22).

The aim of the present review was to carry out an update of the literature on the occupational risk factors involved in breast cancer development, in order to highlight new exposures that are correlated to breast cancer and to provide insight to the way researchers address breast cancer prevention in occupational settings.

\section{Methods}

In the present study, a PubMed/Scholar search was conducted in English journals for studies of breast cancer and occupational risk factors published in peer-reviewed journals. Search terms are summarized in Table I. References from included studies were checked. Accordingly, non-relevant and repeated literatures were excluded. All the abstracts were reviewed and the final set of studies was decided upon. Epidemiological and experimental studies, specifically analyzing occupational exposure and the risk of breast cancer, were included. Any restrictions with regard to place of origin or ethnicity of the women and men, or occupational settings were not placed. Studies of female breast cancer with $\leq 5$ exposed women, and studies of male breast cancer with $<1$ observed or expected case were excluded. In addition, studies in which the exposed group was predominantly workers with $<1$ year employment were excluded. The main characteristics of selected epidemiological studies on occupational exposed workers are summarized in Table II.

\section{Environmental exposure}

General. Breast cancer is not a single disease with variable morphological features and biomarkers, but a group of molecularly distinct neoplastic disorders, as confirmed by numerous studies. Although there is a suggested protective effect of higher parity, lactation and other reproductive factors against the development of breast cancer, currently $5-10 \%$ of breast cancers are linked to hereditary syndromes, and other well-established risk factors represent $30 \%$ of cases. Thus, the risk of breast cancer is not only influenced by the reproductive history and the genetic background but is also thought to be affected by lifestyle factors and exposure to environmental and occupational contaminants $(9,23)$.

An association between occupation and breast cancer was first described at the end of the eighteenth century, when Bernardino Ramazzini revealed a high frequency of breast cancer in nuns, possibly due to their abstinence from sex. Since then, numerous in vivo studies showed that certain chemicals used in occupational settings and, particularly, polybrominated biphenyls, PAHs, polychlorinated biphenyls (PCBs) and other EDCs, have a role in the development of female and male breast cancer (24).

Also in vitro studies demonstrated that environmentally persistent chemicals can determinate genetic damage, 
Table II. Selected published studies of occupational risk factors and breast cancer risk.

\begin{tabular}{|c|c|c|c|c|c|}
\hline Risk factor compound & Authors & Study design & Results & Occupation & (Refs.) \\
\hline \multirow[t]{3}{*}{ Ionising radiation } & Mohan et al & Cohort & Significant association & Radiologic technologists & $(29)$ \\
\hline & Jartti et al & Cohort & Significant association & Physicians & $(30)$ \\
\hline & Doody et al & Cohort & Significant association & Radiologic technologists & $(31)$ \\
\hline \multirow[t]{5}{*}{ Non-ionising radiation } & McElroy et al & Case-control & Significant association & Various & $(37)$ \\
\hline & Coogan et al & Case-control & Significant association & Various & $(16)$ \\
\hline & Dosemeci and Blair & Cohort & Significant association & Telephone industry workers & $(38)$ \\
\hline & Kliukiene et al & Case-control & Significant association & $\begin{array}{l}\text { Radio and telegraph } \\
\text { operators }\end{array}$ & (39) \\
\hline & Forssén et al & Case-control & No significant association & Various & $(40)$ \\
\hline \multirow[t]{2}{*}{ OC pesticides } & Band et al & Case-control & Significant association & Farmers & $(58)$ \\
\hline & Brophy et al & Case-control & Significant association & Various & $(59)$ \\
\hline OP and $\mathrm{OC}$ pesticides & Dolapsakis et al & Case-control & Significant association & Greenhouse workers & (63) \\
\hline OP pesticides & Lerro et al & Cohort & Significant association & $\begin{array}{l}\text { Pesticide applicators } \\
\text { sposuses }\end{array}$ & $(62)$ \\
\hline \multirow[t]{5}{*}{ PAHs } & Petralia et al & Case-control & Significant association & Various & $(81)$ \\
\hline & Costantini et al & Case-control & Significant association & Shoes factory workers & $(82)$ \\
\hline & Walker et al & Cohort & No significant association & $\begin{array}{l}\text { Laundry and dry } \\
\text { cleaning workers }\end{array}$ & (83) \\
\hline & Ruder et al & Cohort & No significant association & Dry-cleaning workers & (84) \\
\hline & Band et al & Case-control & Significant association & $\begin{array}{l}\text { Laundry and dry } \\
\text { cleaning workers }\end{array}$ & $(58)$ \\
\hline \multirow[t]{12}{*}{ Night-shift work } & Davis et al & Case-control & Significant association & Night-shift workers & $(88)$ \\
\hline & Hansen & Case-control & Significant association & Night-shift workers & $(89)$ \\
\hline & Lie et al & Case-control & Significant association & Night-shift workers & $(90)$ \\
\hline & Hansen and Lassen & Case-control & Significant association & Night-shift workers & (91) \\
\hline & Menegaux et al & Case-control & Significant association & Night-shift workers & $(92)$ \\
\hline & Wang et al & Case-control & Significant association & Night-shift workers & (86) \\
\hline & Li et al & Case-control & No significant association & Night-shift workers & (93) \\
\hline & Schernhammer et al & Cohort & Significant association & Night-shift workers & (94) \\
\hline & Åkerstedt et al & Cohort & Significant association & Night-shift workers & $(95)$ \\
\hline & Schwartzbaum et al & Cohort & No significant association & Night-shift workers & $(96)$ \\
\hline & Pronk et al & Cohort & No significant association & Night-shift workers & $(97)$ \\
\hline & Lin et al & Meta-analysis & Significant association & Various & (98) \\
\hline \multirow[t]{3}{*}{ Metals } & Cantor et al & Case-control & Significant association & Various & $(111)$ \\
\hline & Pollan and Gustavsson & Cohort & Significant association & Metal platers and coaters & $(112)$ \\
\hline & Rahim et al & Meta-analysis & No significant association & Various & $(113)$ \\
\hline
\end{tabular}

OP, organophosphate; OC, organochlorine; PAHs, polycyclic aromatic hydrocarbons.

influence cell biological processes and enzymatic activity, or mimic hormone activity.

Thus far, the most well longest-established environmental risk factor of breast cancer is exposure to ionizing radiation. Furthermore, industrial compounds, such as PCBs and agricultural pesticides, have been suggested as risk factors for female breast cancer in several studies (18).

Ionizing radiation exposure. In 2000, the IARC classified $\mathrm{X}$ - and $\gamma$-radiation as carcinogenic agents with sufficient evidence in humans showing a correlation between heavy exposures to ionizing radiation and breast cancer development (15).
In studies of the Japanese population exposed to radiation during the World War II, a statistically significant correlation was identified between female and male breast cancer risk and atomic bomb in survivors of atomic bombings. The risk was 4 -fold greater in women $<20$ years old at the time of the bombing $(25,26)$.

The UNSCEAR reports conclude that there is a considerable evidence for the effects of ionizing radiation exposure on breast cancer rates, with a linear dose-response association (27). The elevated mortality rates for breast cancer are correlated to greater occupational exposures to ionizing radiation until 1950 compared to more recent times. A previous study demonstrated 
the potential health consequences of occupational exposure to ionizing radiation in the medical professions, where breast cancer was more frequently diagnosed compared to other types of cancer (28). Mohan et al (29) evaluated the mortality risks resulting from exposure to low-dose ionizing radiation in a cohort of 146,022 US radiological technologists (73\% women) and identified an elevated risk of fatality from breast cancer among women first employed prior to 1940 compared to those first employed in 1960 or later. Mortality risk was higher among female workers who first operated with fluoroscopy before 1950 compared to those who first were involved in these procedures later.

Jartti et al (30) conducted a cohort study on 1,312 Finnish physicians and observed a slightly elevated risk of breast cancer among physicians occupationally exposed to ionizing radiation in Finland compared to other physicians.

In a study based on a cohort of 56,436 U.S. female radiological technologists, Doody et al (31) evaluated incident breast cancer risks from 1983 to 1998 according to employment characteristics. The study demonstrated that the breast cancer incidence was elevated significantly for those women who began working before 1940 and in women who began working at ages $<17$ years. In a recent review and analysis, occupation as an airline flight personnel has been linked to increased female breast cancer risk in a number of studies. There is uncertainty regarding risk factors, nevertheless increased exposures to cosmic (atmospheric) ionizing radiation could contribute to the increased breast cancer incidence among flight workers (11).

Radiation increases the risk of breast cancer, by directly producing DNA damage and by altering common cellular and intracellular functions. Exposure to ionizing radiation could also enhance breast cancer development by indirectly influencing the ability of hormones or other chemical substances (32).

Recent genetic data indicate that women with certain gene mutations that may increase their susceptibility to develop breast cancer (such as ATM, TP53 and BRCA1/2) may be particularly at risk to the cancer-inducing effects of ionizing radiation exposure $(33,34)$.

Molecular biology studies have shown that genes involved in DNA repair and sensitive to radiation exposure are associated with an increased breast cancer risk. Women with mutated forms of BRCA1 and BRCA2 share an 80\% chance of developing breast cancer during their life (18).

Few studies evaluated the combined role of genetic polymorphisms (such as ATM, TP53 and BRCA1/2) and exposure to ionizing radiation in the etiology of breast cancer in humans; as the genetic mutation or polymorphism of interest is typically extremely rare, additional studies are required to address whether common polymorphisms in DNA repair genes modify the effects of low-dose radiation exposure from medical sources (35).

Thus, it can be concluded that during the early nuclear years, high levels of exposure were recorded for a large number of workers in medical diagnostics, nuclear power industry and in the military, and more recent exposures can be considered to be much lower due to the recognition of the long-term health effects and the introduction of health prevention.

$E M F$. Although not all epidemiological or occupational studies demonstrate that exposure to EMF can cause breast cancer, some of these reported evidence for an increase of the risk following exposure to EMF. IARC classified exposure to low frequency EMF as 'possibly carcinogenic to human', however, the evidence for breast cancer is considered inadequate (36).

A recent case-control study in the US on women who were exposed to low, medium or high EMF levels in their workplace, reported that occupational exposure to EMF may be linked to a slight elevation in breast cancer risk (37).

Several studies have observed an increased risk of breast cancer among female radio and telegraph operators exposed to radiofrequency (1 type of EMF) and extremely low frequency EMF, and in women employed in the telephone industry. Notably, premenopausal women appear to be at a higher risk compared to post-menopausal women $(16,38,39)$.

By contrast, a large case-control study, based on the Swedish population registers, found no evidence of an elevated risk of breast cancer associated with women working in occupations with high EMF exposures (40).

Although mechanisms underling the association between breast cancer and exposure to EMFs are not fully understood, several studies have reported that exposure to EMFs is important for women with estrogen-receptor positive breast tumors, particularly for premenopausal women who produce high levels of estrogens (41-43).

According to several studies, exposure to EMFs may inhibit the synthesis of melatonin by the pineal gland and/or depress the levels of this hormone. As a result, increased circulating levels of estrogens and consequently enhanced proliferation of breast tissue cells have been observed $(44,45)$. In vitro and in vivo studies confirmed this hypothesis by demonstrating the inhibition of the hormone production in blood rats exposed to EMFs, as well as the suppression of mammary tumorigenesis by melatonin (46). However, other studies have not suggested inhibition of melatonin generation in humans mediated by EMFs exposure (47). Additional research is required on this topic to establish the effect of EMFs on initiating breast cancer.

Pesticides. Pesticides constitute a heterogeneous category of chemicals specifically designed for preventing, destroying, repelling or mitigating any pest (48).

Numerous groups of pesticides can be classified and can be grouped according to the target organisms (such as insecticides, fungicides and herbicides), chemical structure (such as organochlorine, organophosphorus, phenoxy acid herbicides, urea and pyrethroids), or type of health hazard produced (49). The association between pesticide exposure and cancerogenesis is actually one of the main issues in occupational and environmental toxicology.

Numerous pesticides have shown carcinogenicity of varying levels. They have also been reported as genotoxic, tumor promoters, immunotoxic and estrogenic (50). As an endocrine disruptor, the pesticide can mimic the actions of different hormones (estrogen or testosterone); thus, it can produce an increase in estrogen-related physiological responses. The pesticide can also behave like an antagonist by binding to the estrogens receptors; thereby, the normal physiological responses associated with estrogen stimulation of its receptor do not occur. Furthermore, the pesticide may interfere with the synthesis, transport, metabolism or elimination of estrogen, causing either an increase or decrease in estrogenic 
effects. Regardless, the normal homeostasis of the system will be disrupted (4).

The class of compounds that has been identified in the past as the most significant chemical agent associated with female cancers includes the organochlorines (OCPs), chlorinated hydrocarbons that are frequently used as pesticides, insecticides or herbicides (19).

The OCPs can persist for extended periods in the environment and in the body; they are detected in the food supply and breast milk, and can be stored in the adipose tissue of animals and humans. Furthermore, they can act like both estrogen agonists and antagonists in several animal experiments (51). Therefore, a possible correlation between breast cancer risk and organochlorine exposure has been hypothesized and investigated over the past decades (52); however, no consistent evidence has been found to support the hypothesis $(53,54)$.

These incongruities may be due to various factors, including biological matrices used to estimate exposure and target samples, with highly varied historical and current pesticide exposure levels and distinct ethnicities, age groups and/or dietary characteristics (55).

Although the majority of OCPs have been banned from use in almost all the industrialized countries, some, such as dichlorodiphenyltrichloroethane (DDT), are the best investigated. There are a few OCPs still in use (endosulfan, lindane and dicofol), which have been associated to several diseases, including breast cancer.

Although there were numerous studies that reported a weak elevation in the levels of DDT and the incidence of breast cancer, none were statistically significant. Rural populations of agricultural works and their families who may be exposed to higher doses of OCPs, such as DDT, compared to the general population, have been reported to have a higher incidence of breast cancer compared to the populations not exposed. Retrospective studies have produced conflicting results due to certain limits, such as small sample size, difficulty in measuring pesticide exposure, and correlating blood pesticide levels to the progression of breast cancer (4).

Cohn et al (56) investigated whether serum $p, p^{\prime}$-DDT and $o, p^{\prime}$-DDT are associated with breast cancer, using blood samples obtained prior to the banning of DDT and when the use of this pesticide was extremely high. These results are consistent with the hypothesis that $p, p^{\prime}$-DDT exposure in life was retained longer, possibly due to slower metabolism, and may increase the breast cancer risk.

In a study of a population from the Canary Islands (Spain), Boada et al (57) demonstrated that an organochlorine pesticide mixture, including aldrin, $p, p^{\prime}$-DDE and dichlorodiphenyldichloroethane, could have a relevant role in breast cancer development.

Band et al (58) identified a significant association in the combined group of pre- and post-menopausal women, notably in crop farmers and in fruit and vegetable farming.

Brophy et al (59), in an exploratory population-based case-control study, identified an elevated risk for developing breast cancer in the agricultural population, suggesting the importance for evaluating environmental risk factors and detailed occupational histories of cancer patients.

Other classes of popular pesticides have replaced OCPs over the years in a continuing search for less toxic, but effective, agents. Organophosphates (OPs) were formerly among the most widely used household pesticides, representing $22 \%$ of non-agricultural usage in 2001 (50).

Malathion and diazinon are probably carcinogenic to humans (group 2A), and dichlorvos, parathion and tetrachlorvinphos are classified as possibly carcinogenic to humans (group 2B) (60); parathion is considered as 'a possible human carcinogen' by the US Environmental Protection Agency (61). An increased cancer risk has been associated with several OP insecticides in epidemiological studies; however, the majority of studies on OP use and cancer outcomes have largely been conducted in predominantly male populations. Consequently, little is known regarding the potential impact of personal OP use among women, specifically on the development of female cancers, despite the fact that OPs as a class are thought to have endocrine-disrupting properties (62). This is possibly due to the fact that male workers are more engaged in pesticide handling compared to female subjects (48).

However, in a preliminary study, Dolapsakis et al (63) evaluated whether occupational exposure to pesticides in greenhouses (mainly OPs and organocarbamates) may enhance the risk of malignant or premalignant findings in mammographic examination. The study concluded that women exposed to pesticides may have higher risks of incidence for a number of lesions, which are risk markers for subsequent invasive breast cancers. Recently, possible evidence of chlorpyrifos estrogenicity has been reported (64).

In a study aimed to prospectively examine the use of OP insecticides and risk of multiple cancer sites among women, associations with several cancer sites were observed, including thyroid, ovary and breast. The increased risks that they observed for hormonally-related cancers are consistent with the hypothesis that OPs may act as endocrine disruptors, although additional studies exploring this and other possible mechanisms are required (62).

Carbamates are another class of widely used insecticides. Carbaryl has been classified as a group III carcinogenic (unclassifiable as to human carcinogenicity) from the IARC (65). Carbamates could inhibit $17 \mathrm{~b}$-estradiol and progesterone activity in human breast and endometrial cancer cells (66). Recently, the carbamate fungicide benomyl has been reported as a risk factor for breast cancer by acting as an endocrine disruptor (67).

Synthetic pyrethroids, some of the most common pesticides in current use, have been investigated for their potential estrogenic activity; thus it has been demonstrated that this class of pesticide may contribute to produce breast cancer in human cells $(68,69)$.

Although the majority of studies on carcinogenesis agree upon the fact that pesticides can cause breast cancer acting like endocrine disruptors, recent evidence also suggest that their adverse effects may be associated with the interactions with the aryl hydrocarbon receptor (AhR), a transcription factor that regulates xenobiotic metabolism enzymes that belong to the cytochrome P450 1A family (including CYP1A1 and CYP1B1 enzymes). Thereby, it is considered as a mediator of toxicity during environmental pollutant metabolism. Long-term exposure to pesticides could activate AhR and the estrogen receptor, which may affect the expression of genes regulated by the AhR-ER crosstalk, thus producing 
an imbalance between CYP1A1 and CYP1B1 enzymes. This mechanism could lead to the accumulation of DNA adducts and represent a potential initial factor involved in mammary carcinogenesis (70). According to L'Héritier et al (70), genes involved in the aforementioned crosstalk could become important biomarkers to evaluate potential long-term effects of pesticides on breast cancer.

PAHs. PAHs are ubiquitous environmental pollutants that are generated primarily through incomplete combustion of carbon-containing materials, including coals, crude oil, wood, gasoline, foods and cigarettes (71). Therefore, higher exposures to PAHs occur among selected occupations, such as firefighters and coke oven, aluminium and foundry workers [Knower et al (22)].

Substantial epidemiological evidence suggests that long-term exposure to PAH-rich emissions is associated with a higher lung cancer risk in exposed workers (IARC 2005) (71). However, the carcinogenic properties of PAHs in human breast cancer remain to be elucidated. Using PAH-DNA adducts as a body burden measure of exposure and response, epidemiological studies have observed a positive association with breast cancer among women (72).

In 1996, Li et al (73) evaluated aromatic DNA adducts in normal adjacent tissues from 87 breast cancer patients and in normal tissues of 29 reduction mammoplasty non-cancer controls. A significantly higher level of aromatic DNA adducts was identified in adjacent breast tissues of cancer patients compared to non-cancer controls, supporting the hypothesis that environmental carcinogen exposure may contribute to human breast cancers.

PAH-DNA adducts reflect short-term exposures, whereas breast cancer is believed to develop over a number of years (74). Thus, it is of interest to evaluate longer-term PAH exposures in association with breast cancer risk. In 2015, Mordukhovich et al (75) observed positive associations between vehicular traffic-related benzo[a]pyrene (BaP) exposure and breast cancer incidence among women with comparatively high long-term traffic $\mathrm{BaP}$ exposures, although effect estimates were imprecise.

Gene-specific methylation of RAR $\beta$, and perhaps APC, may interact with PAH-DNA adducts to increase risk of hormone receptor-positive breast cancer. There was little evidence that adducts were associated with or interacted with other methylation markers of interest (76).

In a small-scale, case-control study of breast cancer, Li et al (77) made several interesting and important observations, such as a high level of in vitro BaP-induced DNA adducts was a significant risk factor for breast cancer; environmental carcinogen exposure may modify individual susceptibility to carcinogen exposure and in turn the risk of breast cancer. When breast tissues were exposed in vitro to a classic tobacco carcinogen, $\mathrm{BaP}$, women with breast cancer exhibited a significantly higher level of BaP-DNA adducts compared to the healthy controls. Following adjustment for several confounding factors, the level of BaP-induced DNA adducts was identified as a significant risk factor for breast cancer. As all the tissue samples were exposed to the same level of BP under the same experimental conditions, the level of DNA adducts detected in the present study reflects intrinsic factors that determine the tissue response to such damage, such as carcinogen metabolism and DNA repair capacities. The higher level of DNA damage among cases thus suggests that cases had an elevated activation, deficient detoxification and reduced DNA repair capacity compared with controls (77).

PAHs metabolism occurs in the liver by cytochrome P450 (such as CYP1A1), which could activate the aryl hydrocarbon hydroxylase $(\mathrm{AHH})$. Genotypic variants of CYP1A1 can improve increased $\mathrm{AHH}$ function. Several studies suggest that women with the variant genotype(s) have a higher risk to develop breast cancer compared to women with the normal genotype (8).

Rundle et al (78) reported that the null variant of the detoxifying gene GSTM1 was associated with adduct levels in cases, but not in controls. These results suggest that the GSTM1 polymorphism has a role in the formation of PAH-DNA adducts, thus preventing accumulation of environmental damage in breast tissue.

Benzene is chemical solvent involved in several hematological diseases, such as leukemia and myelodysplastic syndrome (79). Experimental studies demonstrated that exposure to benzene can induce breast cancer (80). However, few studies on humans have shown that benzene is involved in breast cancer development. A case-control study by Petralia et al (81) suggested an association between breast cancer risk and occupational exposure to benzene in women. In addition, Costantini et al (82) conducted an epidemiological cohort study of female workers using benzene-based glues in a shoe factory in Italy. The study demonstrated that chronic exposure to benzene can be one of the risk factor for breast cancer.

Further studies also examined the role of several solvents, such as 1,1-dichloroethane, 1,2-dichloroethane, 1,2-dichloropropane, dichloromethane and tetrachloroethylene, which are commonly used in industrial settings. However, the majority of the studies did not report substantial results $(83,84)$. Recently, Band et al (58) observed a 4.9-fold increased risk of breast cancer among postmenopausal women employed in laundry and dry cleaning.

Night-shift work. In 2007, an expert group of the IARC, based on strong animal and weak human evidence, classified night-shift shift work as a possible cause of breast cancer (group 2A) (10). In Scandinavia, where the association between breast cancer and night-shift work appears to be an issue, numerous studies have been carried out (85); however, there were also certain studies that did not report any association, possibly due to differences in night-shift work evaluation, study design, recall bias and incomplete adjustment for confounding factors (86).

Nurses and flight personnel represent 2 of the main occupational populations investigated in epidemiological studies of night-shift work. Otherwise, few studies referred to the general population (87).

The epidemiological evidence of an association between shift work and breast cancer risk among women is based on case-control and cohort studies; some of them identified a positive association, however, others reported no association. A positive correlation between shift work and breast cancer risk was described in several case-control studies, which highlighted that the breast cancer risk is associated with 
characteristics of night work, and provided new evidence that night work may have a role in the occurrence of the disease (88-92). More recently, in 2015, a positive correlation between breast cancer risk and night-shift work was reported by Wang et al (86). In particular, the combined effects of night-shift work with no daytime napping or longer sleep duration are greater compared to the independent effects. By contrast, Li et al (93) showed a negative correlation between shift work and breast cancer risk in the Chinese population, suggesting that the effect of shift work on breast cancer development may be different in Asian and Caucasian women.

Schernhammer et al (94) performed 2 large prospective cohort studies to assess the risk of breast cancer among nurses following their rotating night-shift work. The study demonstrated that the risk of breast cancer was statistically significantly elevated in postmenopausal women who worked for $\geq 30$ years on rotating night-shifts, compared with those who never worked rotating night-shifts. Among premenopausal women an increased breast cancer risk of 23\% after 1-14 years of shift work was observed. Additionally, the results of a recent study showed a significant association between exposure to night work for $>20$ years and breast cancer in women who were followed up to the age of 60 years (95). By contrast, different results were reported by Schwartzbaum et al (96) and by Pronk et al (97). These studies did not identify any evidence for an association between shift work and breast cancer incidence rates.

Recently, a meta-analysis of prospective cohort studies supports the idea that there is a positive dose-effects association between night-shift work and morbidity of breast cancer (98).

In order to explain the mechanisms involved in breast cancer development and potentially associated carcinogenic effects of circadian rhythm disruption, a variety of mechanisms has been suggested (99).

According to mechanistic hypotheses, exposure to light at night suppresses the nocturnal peak of melatonin and the circadian master clock, while sleep disruption produces negative effects on the immune system. All these factors could cause asynchronous cell proliferation of breast tissue (100).

The first suggestion that the globally increasing use of electric lighting at night may alter melatonin homeostasis and contribute to the breast cancer development was made in 1987 by Stevens $(11,99)$.

Melatonin may act on initiation, promotion and progression of tumors. A decrease of melatonin production favors an upregulation of the gonadal axis, thus causing an increased in circulating levels of estrogens, which is a well-known risk factor for breast cancer. Additionally, melatonin can activate the glutathione antioxidative pathways. Furthermore, melatonin acts as a response modifier to estrogens: i) Exerts an anti-estrogenic effect with interaction with estrogen receptor $\alpha(E R \alpha)$; ii) counteracts the effect of estradiol on breast cancer cell proliferation, invasiveness and telomerase activity; iii) downregulates the expression of protein growth factors and the proto-oncogenes stimulated by estrogens; and iv) downregulates the human epidermal growth factor receptor 2 (HER2/neu) (101).

Recently, a genetic variation in the genes involved in the circadian rhythm pathway has been an important topic of debate. Several studies have also examined genetic variants in circadian genes associated with the breast cancer risk, but only the core circadian genes and a limited number of single-nucleotide polymorphisms (SNPs) in each gene were evaluated in epidemiological studies $(102,103)$. Furthermore, it has been hypothesized that genetic polymorphisms in the circadian pathway genes can increase the risk of breast cancer among women working at night (104). In a recent study by Truong et al (100), the analysis of individual SNPs showed a strong association between breast cancer and rs11932595 in CLOCK and rs1482057 in RORA genes in postmenopausal women, but not in in premenopausal women. The study suggested that circadian genes may have a role in breast cancer etiology. However, further studies are required in order to clarify the role of specific combination of SNPs of the circadian rhythm pathway in breast cancer development.

Metals. A number of heavy metals are naturally present in the environment in small concentrations; however, as a consequence of their increased use in several occupational settings, heavy metals can be considered as environmental contaminants (105).

The main global sources of anthropogenic contamination by heavy metals include different industrial places, such as power industry, transport, municipal waste management, waste dumping sites, fertilizers and waste used to fertilize soil. Emission of heavy metals into the environment occurs through a wide range of processes and pathways, including to the air (such as combustion, extraction and processing), to surface water (through direct deposition, runoff and releases from storage and transport), and to the soil (and hence into crops and other organisms through the food chain) (106).

It is also generally accepted that some of these metals are essential for living organisms in small quantities, but toxic in higher concentrations or in other speciation forms, including copper $(\mathrm{Cu})$, chromium $(\mathrm{Cr})$, manganese and zinc $(\mathrm{Zn})$, while metabolic roles have been demonstrated for others, such as cadmium $(\mathrm{Cd})$, mercury $(\mathrm{Hg})$ and lead $(\mathrm{Pb})$, which are considered as obligatory toxic. Numerous heavy metals appear to be involved in the development of several types of cancer (including arsenic, beryllium, $\mathrm{Cd}$, nickel and hexavalent $\mathrm{Cr}$ ), acting like potential endocrine disruptors or metalloestrogens (4).

Metalloestrogens are small ionic metals and metalloids that can function as endocrine disruptors by mimicking the action of estrogens. Two different classes of metalloestrogens can be distinguished: The first includes oxyanions, arsenite, antimony, nitrite, selenite and vanadate; the second consists of bivalent cations, including $\mathrm{Cd}$, calcium, cobalt, $\mathrm{Cu}$, nickel, $\mathrm{Cr}, \mathrm{Pb}, \mathrm{Hg}$ and tin. Metalloestrogens can activate the estrogen receptor in the absence of estradiol; thus exposure to these metals may increase the risk of developing breast cancer. In support of this hypothesis, environmental exposure to a number of the metalloestrogens is widespread and has increased significantly over the last 50-60 years. The majority of the metalloestrogens also have a long biological half life (for example, $\mathrm{Cd}$ has a half life of 10-30 years) and accumulate in the body and in the mammary tissue.

There are several studies that support the idea that exposure to $\mathrm{Cd}$ is linked to an increased risk of developing breast cancer (107). Cd is a widespread metallic element occurring in the environment naturally (such as volcanic activity, weathering of Cd-containing rocks and sea spray) and as a pollutant 
deriving from industrial (such as batteries, coatings and plastic stabilizers), agricultural (such as contamination of phosphate fertilizers) and other sources (such as release from motor vehicle fuel combustion and tire wear) (108).

Evidence obtained from in vivo and in vitro studies strongly suggests that $\mathrm{Cd}$ can act like a metalloestrogen, binding itself to $\mathrm{ER} \alpha$ (with an equilibrium dissociation constant nearly equivalent to that of estradiol), activate it, and induce expression of certain ER target genes (109). Additionally, Cd produces other estrogen-like effects, including increased uterine weight; changes in uterine lining; increased epithelial cell density in mammary glands; increased cell proliferation; and increased aneuploidy (110).

In a study by Cantor et al (111), using a case-control method, mortality records from 24 American states were used to evaluate occupational exposures as a possible cause of breast cancer. The death certificates were coded for occupation and industry. Following adjustment for several confounding factors, associations for probability and level of exposure were found for several metals/metal oxides, in particular workplace exposure to $\mathrm{Cd}$ was associated with an $8-20 \%$ increase in the breast cancer risk among Caucasian women and a $50-130 \%$ increase in the risk among African-American women.

A second epidemiological study in a retrospective cohort of working Swedish women also suggests a link between occupational exposure to $\mathrm{Cd}$ and an increased risk of breast cancer. In this study, women employed as metal platers and coaters and exposed to $\mathrm{Cd}$ exhibited a significant excess risk to develop breast cancer (112). Although these epidemiological studies suggest a link between $\mathrm{Cd}$ and breast cancer, more experimental and epidemiological studies are required in order to establish a cause-effect association between exposure to $\mathrm{Cd}$ and development of the disease.

In a recent meta-analysis on 13 studies including 978 exposed cases and 1,279 controls, several reviewed evidence suggesting that exposure to $\mathrm{Cd}$ is a cause of breast cancer. The results indicated that the frequencies of breast cancer were not significantly higher in the $\mathrm{Cd}$-exposed group compared to the controls; thus, exposure to $\mathrm{Cd}$ could not significantly induce the breast cancer (113).

Similar to $\mathrm{Cd}$, nickel is able to bind to $\mathrm{ER} \alpha$, promote cell proliferation and induce aneuploidy. However, further studies at the animal, cellular, and molecular levels are required to demonstrate whether and how low-dose, chronic nickel exposure can lead to breast cancer. As much less is known regarding the nickel-binding site compared to the Cd-binding site on $\mathrm{ER} \alpha$, more structural studies are necessary as well to confirm the role of nickel as a metalloestrogen (105).

Certain metal elements, such as $\mathrm{Zn}$, iron, $\mathrm{Cu}, \mathrm{Cr}$ and $\mathrm{Pb}$, can cause proliferation of malignant cells in breast cancer development. The resulting destabilization of the genetic material cause the synthesis of mutant p53 protein, the block of apoptosis and regulatory effects of cells. This can lead to tumor progression and the destabilization of the genome, which is represented by increased DNA fragmentation (114).

\section{Conclusions}

Breast cancer is a complex multifactorial disease, from its initiation to its progression. Current literature is not unanimous regarding the specific clinical and pathological characteristics of breast cancer possibly linked to occupational settings. In addition, there are no molecular biomarkers that can be used specifically to identify occupational exposures associated with breast cancer. These exposures may be mediated by environmental factors, such as lifestyle (diet, alcohol consumption and smoking habits), work-correlated features (including shift work), and other individual conditions. Although there are a number of experimental studies on the ability of several compounds to cause breast tissue development in rodent models, there are few published studies that have demonstrated cancer development in humans. The assessment of the exposures should possibly consider the short window of time when the structures of the gland are more sensitive.

As breast cancer is a multifactorial disease, the evaluation of occupational factors is hardly considered in the overall risks assessment and there is a requirement to include them in occupational hazard and risk assessments by a multidisciplinary investigation and interdisciplinary cooperation. Experimental models may be developed in order to evaluate interactions between lifestyle factors, such as circadian rhythms, diet and physical activities, and occupational exposure that may provide critical information on human variability, which is also dependent on epigenetic reprogramming. Therefore, the development of environmental epigenetic biomarkers may be more suitable for the prediction of future disease risk, including that for breast cancer.

\section{References}

1. American Cancer Society: Cancer Facts and Figures 2014 American Cancer Society, Atlanta, GA, 2014.

2. World Health Organization: Cancer Country Profiles, 2014. World Health Organization, Geneva, 2014.

3. DeSantis CE, Bray F, Ferlay J, Lortet-Tieulent J, Anderson BO and Jemal A: International Variation in Female Breast Cancer Incidence and Mortality Rates. Cancer Epidemiol Biomarkers Prev 24: 1495-1506, 2015.

4. Wallace DR: Environmental Pesticides and Heavy Metals - Role in Breast Cancer. In: Toxicity and Hazard of Agrochemicals. Larramendy ML and Soloneski S (eds). InTech, Rijeka, 2015.

5. Colditz GA: Breast Cancer Epidemiology and Risk Factors. http//emedicine.medscape.com. Accessed November 29, 2015.

6. Weiderpass E, Meo M and Vainio H: Risk factors for breast cancer, including occupational exposures. Saf Health Work 2: $1-8,2011$.

7. McPherson K, Steel CM and Dixon JM: ABC of breast diseases. Breast cancer-epidemiology, risk factors, and genetics. BMJ 321: 624-628, 2000.

8. Brody JG, Moysich KB, Humblet O, Attfield KR, Beehler GP and Rudel RA: Environmental pollutants and breast cancer: epidemiologic studies. Cancer 109 (Suppl 12): 2667-2711, 2007.

9. Fredslund SO and Bonefeld-Jørgensen EC: Breast cancer in the Arctic - changes over the past decades. Int J Circumpolar Health 71: 19155, 2012.

10. IARC Working Group on the Evaluation of Carcinogenic Risks to Humans: Painting, firefighting, and shiftwork. IARC Monogr Eval Carcinog Risks Hum 98: 9-764, 2010.

11. Slack R, Young C and Rushton L; British Occupational Cancer Burden Study Group: Occupational cancer in Britain. Female cancers: Breast, cervix and ovary. Br J Cancer 107 (Suppl 1): S27-S32, 2012.

12. Lie JA, Andersen A and Kjaerheim K: Cancer risk among 43000 Norwegian nurses. Scand J Work Environ Health 33: 66-73, 2007.

13. Dimich-Ward H, Lorenzi M, Teschke K, Spinelli JJ, Ratner PA, Le ND, Chow Y, Shu D and Gallagher RP: Mortality and cancer incidence in a cohort of registered nurses from British Columbia, Canada. Am J Ind Med 50: 892-900, 2007. 
14. Hansen J and Stevens RG: Case-control study of shift-work and breast cancer risk in Danish nurses: Impact of shift systems. Eur J Cancer 48: 1722-1729, 2012.

15. No authors listed: Ionizing radiation, part 1: $\mathrm{X}$ - and gamma-radiation, and neutrons. Overall introduction. IARC Monogr Eval Carcinog Risks Hum 75 Pt 1: 35-115, 2000.

16. Coogan PF, Clapp RW, Newcomb PA, Wenzl TB, Bogdan G, Mittendorf R, Baron JA and Longnecker MP: Occupational exposure to 60-hertz magnetic fields and risk of breast cancer in women. Epidemiology 7: 459-464, 1996.

17. Brody JG and Rudel RA: Environmental pollutants and breast cancer. Environ Health Perspect 111: 1007-1019, 2003.

18. Kruk J and Aboul-Enein HY: Environmental exposure, and other behavioral risk factors in breast cancer. Curr Cancer Ther Rev 2 : 3-21, 2006.

19. Macon MB and Fenton SE: Endocrine disruptors and the breast: Early life effects and later life disease. J Mammary Gland Biol Neoplasia 18: 43-61, 2013.

20. Birnbaum LS and Fenton SE: Cancer and developmental exposure to endocrine disruptors. Environ Health Perspect 111: 389-394, 2003.

21. Fenton SE: Endocrine-disrupting compounds and mammary gland development: early exposure and later life consequences. Endocrinology 147 (Suppl 6): S18-S24, 2006

22. Knower KC, To SQ, Leung YK, Ho SM and Clyne CD: Endocrine disruption of the epigenome: a breast cancer link. Endocr Relat Cancer 21: T33-T55, 2014.

23. Petracci E, Decarli A, Schairer C, Pfeiffer RM, Pee D, Masala G, Palli D and Gail MH: Risk factor modification and projections of absolute breast cancer risk. J Natl Cancer Inst 103: 1037-1048, 2011.

24. Franco G: Occupation and breast cancer: Fitness for work is an aspect that needs to be addressed. Med Lav 104: 87-92, 2013.

25. Tokunaga M, Land CE, Tokuoka S, Nishimori I, Soda M and Akiba S: Incidence of female breast cancer among atomic bomb survivors, 1950-1985. Radiat Res 138: 209-223, 1994.

26. Land CE: Studies of cancer and radiation dose among atomic bomb survivors. The example of breast cancer. JAMA 274 402-407, 1995

27. United Nations Scientific Committee on the Effects of Atomic Radiation (UNSCEAR): Effects of Ionizing Radiation. In UNSCEAR 2006 Report to the General Assembly with Scientific Annexes. Vol 1. United Nations, New York, NY, 2008.

28. Chobanova N, Vukov M and Yagova A: Cancer incidence among Bulgarian medical radiation workers: Epidemiological study. J BUON 12: 65-69, 2007

29. Mohan AK, Hauptmann M, Freedman DM, Ron E, Matanoski GM, Lubin JH, Alexander BH, Boice JD Jr, Doody MM and Linet MS: Cancer and other causes of mortality among radiologic technologists in the United States. Int J Cancer 103: 259-267, 2003.

30. Jartti P, Pukkala E, Uitti J and Auvinen A: Cancer incidence among physicians occupationally exposed to ionizing radiation in Finland. Scand J Work Environ Health 32: 368-373, 2006

31. Doody MM, Freedman DM, Alexander BH, Hauptmann M Miller JS, Rao RS, Mabuchi K, Ron E, Sigurdson AJ and Linet MS: Breast cancer incidence in U.S. radiologic technologists. Cancer 106: 2707-2715, 2006.

32. Calaf GM and Hei TK: Establishment of a radiation- and estrogen-induced breast cancer model. Carcinogenesis 21: 769-776, 2000

33. Andrieu N, Easton DF, Chang-Claude J, Rookus MA, Brohet R, Cardis E, Antoniou AC, Wagner T, Simard J, Evans G, et al: Effect of chest X-rays on the risk of breast cancer among BRCA $1 / 2$ mutation carriers in the international BRCA1/2 carrier cohort study: A report from the EMBRACE, GENEPSO, GEO-HEBON, and IBCCS Collaborators' Group. J Clin Oncol 24: 3361-3366, 2006.

34. Millikan RC, Player JS, Decotret AR, Tse CK and Keku T: Polymorphisms in DNA repair genes, medical exposure to ionizing radiation, and breast cancer risk. Cancer Epidemiol Biomarkers Prev 14: 2326-2334, 2005.

35. Ronckers CM, Erdmann CA and Land CE: Radiation and breast cancer: A review of current evidence. Breast Cancer Res 7: 21-32, 2005.

36. IARC Working Group on the Evaluation of Carcinogenic Risks to Humans: Non-ionizing radiation, Part 1: static and extremely low-frequency (ELF) electric and magnetic fields. IARC Monogr Eval Carcinog Risks Hum 80: 1-395, 2002.
37. McElroy JA, Egan KM, Titus-Ernstoff L, Anderson HA, Trentham-Dietz A, Hampton JM and Newcomb PA: Occupational exposure to electromagnetic field and breast cancer risk in a large, population-based, case-control study in the United States. J Occup Environ Med 49: 266-274, 2007.

38. Dosemeci M and Blair A: Occupational cancer mortality among women employed in the telephone industry. J Occup Med 36: 1204-1209, 1994.

39. Kliukiene J, Tynes T and Andersen A: Follow-up of radio and telegraph operators with exposure to electromagnetic fields and risk of breast cancer. Eur J Cancer Prev 12: 301-307, 2003.

40. Forssén UM, Rutqvist LE, Ahlbom A and Feychting M: Occupational magnetic fields and female breast cancer: A case-control study using Swedish population registers and new exposure data. Am J Epidemiol 161: 250-259, 2005.

41. Caplan LS, Schoenfeld ER, O'Leary ES and Leske MC: Breast cancer and electromagnetic fields--a review. Ann Epidemiol 10: 31-44, 2000.

42. Ahlbom IC, Cardis E, Green A, Linet M, Savitz D and Swerdlow A; ICNIRP (International Commission for Non-Ionizing Radiation Protection) Standing Committee on Epidemiology: Review of the epidemiologic literature on EMF and Health. Environ Health Perspect 109 (Suppl 6): 911-933, 2001.

43. Erren TC: A meta-analysis of epidemiologic studies of electric and magnetic fields and breast cancer in women and men. Bioelectromagnetics 5 (Suppl 5): S105-S119, 2001.

44. Stevens RG: Electric power use and breast cancer: A hypothesis. Am J Epidemiol 125: 556-561, 1987.

45. Kato M,Honma K, Shigemitsu T and Shiga Y: Effects of exposure to a circularly polarized $50-\mathrm{Hz}$ magnetic field on plasma and pineal melatonin levels in rats. Bioelectromagnetics 14: 97-106, 1993.

46. Hill SM and Blask DE: Effects of the pineal hormone melatonin on the proliferation and morphological characteristics of human breast cancer cells (MCF-7) in culture. Cancer Res 48: 6121-6126, 1988.

47. Graham C, Cook MR and Riffle DW: Human melatonin during continuous magnetic field exposure. Bioelectromagnetics 18: 166-171, 1997.

48. Fenga C, Gangemi S, Catania S, De Luca A and Costa C: IL-17 and IL-22 serum levels in greenhouse workers exposed to pesticides. Inflamm Res 63: 895-897, 2014.

49. World Health Organization (WHO): The WHO recommended classification of pesticides by hazard and guidelines to classification 2009. World Health Organisation, Geneva, 2010.

50. Teitelbaum SL, Gammon MD, Britton JA, Neugut AI, Levin B and Stellman SD: Reported residential pesticide use and breast cancer risk on Long Island, New York. Am J Epidemiol 165: 643-651, 2007.

51. Snedeker SM: Pesticides and breast cancer risk: A review of DDT, DDE, and dieldrin. Environ Health Perspect 109 (Suppl 1): 35-47, 2001.

52. Adami HO, Lipworth L, Titus-Ernstoff L, Hsieh CC, Hanberg A, Ahlborg U, Baron J and Trichopoulos D: Organochlorine compounds and estrogen-related cancers in women. Cancer Causes Control 6: 551-566, 1995.

53. Høyer AP, Jørgensen T, Rank F and Grandjean P: Organochlorine exposures influence on breast cancer risk and survival according to estrogen receptor status: A Danish cohort-nested case-control study. BMC Cancer 1: 8, 2001.

54. Salehi F, Turner MC, Phillips KP, Wigle DT, Krewski D and Aronson KJ: Review of the etiology of breast cancer with special attention to organochlorines as potential endocrine disruptors. J Toxicol Environ Health B Crit Rev 11: 276-300, 2008

55. Arrebola JP, Belhassen H, Artacho-Cordón F, Ghali R, Ghorbel H, Boussen H, Perez-Carrascosa FM, Expósito J, Hedhili A and Olea N: Risk of female breast cancer and serum concentrations of organochlorine pesticides and polychlorinated biphenyls: A case-control study in Tunisia. Sci Total Environ 520: 106-113, 2015.

56. Cohn BA, Wolff MS, Cirillo PM and Sholtz RI: DDT and breast cancer in young women: New data on the significance of age at exposure. Environ Health Perspect 115: 1406-1414, 2007.

57. Boada LD, Zumbado M, Henríquez-Hernández LA Almeida-González M, Alvarez-León EE, Serra-Majem L and Luzardo OP: Complex organochlorine pesticide mixtures as determinant factor for breast cancer risk: A population-based case-control study in the Canary Islands (Spain). Environ Health 11: 28, 2012 . 
58. Band PR, Le ND, Fang R, Deschamps M, Gallagher RP and Yang P: Identification of occupational cancer risks in British Columbia. A population-based case-control study of 995 incident breast cancer cases by menopausal status, controlling for confounding factors. J Occup Environ Med 42: 284-310, 2000.

59. Brophy JT, Keith MM, Watterson A, Park R, Gilbertson M, Maticka-Tyndale E, Beck M, Abu-Zahra H, Schneider K, Reinhartz A, et al: Breast cancer risk in relation to occupations with exposure to carcinogens and endocrine disruptors: A Canadian case-control study. Environ Health 11: 87, 2012.

60. International Agency for Research on Cancer (IARC): IARC Monographs Volume 112: evaluation of five organophosphate insecticides and herbicides. World Health Organization, Lyon, 2015.

61. U.S. Environmental Protection Agency (U.S. EPA): Integrated Risk Information System (IRIS) on Parathion. National Center for Environmental Assessment, Office of Research and Development, Washington, DC, 1999.

62. Lerro CC, Koutros S, Andreotti G, Friesen MC, Alavanja MC, Blair A, Hoppin JA, Sandler DP, Lubin JH, Ma X, et al: Organophosphate insecticide use and cancer incidence among spouses of pesticide applicators in the Agricultural Health Study. Occup Environ Med 72: 736-744, 2015.

63. Dolapsakis G, Vlachonikolis IG, Varveris C and Tsatsakis AM: Mammographic findings and occupational exposure to pesticides currently in use on Crete. Eur J Cancer 37: 1531-1536, 2001.

64. Andersen HR, Vinggaard AM, Rasmussen TH, Gjermandsen IM and Bonefeld-Jørgensen EC: Effects of currently used pesticides in assays for estrogenicity, androgenicity, and aromatase activity in vitro. Toxicol Appl Pharmacol 179: 1-12, 2002.

65. No authors listed: Some carbamates, thiocarbamates and carbazides. IARC Monogr Eval Carcinog Risk Chem Man 12: $1-282,1976$

66. Klotz DM, Arnold SF and McLachlan JA: Inhibition of 17 beta-estradiol and progesterone activity in human breast and endometrial cancer cells by carbamate insecticides. Life Sci 60 $1467-1475,1997$.

67. Kawaratani Y, Matsuoka T, Hirata Y, Fukata N, Nagaoka Y and Uesato S: Influence of the carbamate fungicide benomyl on the gene expression and activity of aromatase in the human breast carcinoma cell line MCF-7. Environ Toxicol Pharmacol 39: 292-299, 2015

68. Garey J and Wolff MS: Estrogenic and antiprogestagenic activities of pyrethroid insecticides. Biochem Biophys Res Commun 251: 855-859, 1998

69. Jin M, Li L, Xu C, Wen Y and Zhao M: Estrogenic activities of two synthetic pyrethroids and their metabolites. J Environ Sci (China) 22: 290-296, 2010

70. L'Héritier F, Marques M, Fauteux M and Gaudreau L: Defining molecular sensors to assess long-term effects of pesticides on carcinogenesis. Int J Mol Sci 15: 17148-17161, 2014.

71. Deng Q, Huang S, Zhang X, Zhang W, Feng J, Wang T, Hu D Guan L, Li J, Dai X, et al: Plasma microRNA expression and micronuclei frequency in workers exposed to polycyclic aromatic hydrocarbons. Environ Health Perspect 122: 719-725, 2014

72. Gammon MD, Sagiv SK, Eng SM, Shantakumar S, Gaudet MM, Teitelbaum SL, Britton JA, Terry MB, Wang LW, Wang Q, et al: Polycyclic aromatic hydrocarbon-DNA adducts and breast cancer: A pooled analysis. Arch Environ Health 59: 640-649, 2004.

73. Li D, Wang M, Dhingra K and Hittelman WN: Aromatic DNA adducts in adjacent tissues of breast cancer patients: Clues to breast cancer etiology. Cancer Res 56: 287-293, 1996.

74. Gammon MD, Santella RM, Neugut AI, Eng SM, Teitelbaum SL, Paykin A, Levin B, Terry MB, Young TL, Wang LW, et al: Environmental toxins and breast cancer on Long Island. I. Polycyclic aromatic hydrocarbon DNA adducts. Cancer Epidemiol Biomarkers Prev 11: 677-685, 2002.

75. Mordukhovich I, Beyea J, Herring AH, Hatch M, Stellman SD, Teitelbaum SL, Richardson DB, Millikan RC, Engel LS, Shantakumar S, et al: Vehicular Traffic-Related Polycyclic Aromatic Hydrocarbon Exposure and Breast Cancer Incidence: The Long Island Breast Cancer Study Project (LIBCSP). Environ Health Perspect: May 22, 2015 (Epub ahead of print).

76. White AJ, Chen J, McCullough LE, Xu X, Cho YH, Teitelbaum SL, Neugut AI, Terry MB, Hibshoosh H, Santella RM, et al: Polycyclic aromatic hydrocarbon (PAH)-DNA adducts and breast cancer: Modification by gene promoter methylation in a population-based study. Cancer Causes Control 26: 1791-1802, 2015 .
77. Li D, Wang M, Firozi PF, Chang P, Zhang W, Baer-Dubowska W, Moorthy B, Vulimiri SV, Goth-Goldstein R, Weyand EH, et al: Characterization of a major aromatic DNA adduct detected in human breast tissues. Environ Mol Mutagen 39: 193-200, 2002.

78. Rundle A, Tang D, Zhou J, Cho S and Perera F: The association between glutathione S-transferase M1 genotype and polycyclic aromatic hydrocarbon-DNA adducts in breast tissue. Cancer Epidemiol Biomarkers Prev 9: 1079-1085, 2000.

79. Smith MT, Jones RM and Smith AH: Benzene exposure and risk of non-Hodgkin lymphoma. Cancer Epidemiol Biomarkers Prev 16: 385-391, 2007.

80. Wolff MS, Collman GW, Barrett JC and Huff J: Breast cancer and environmental risk factors: Epidemiological and experimental findings. Annu Rev Pharmacol Toxicol 36: 573-596, 1996.

81. Petralia SA, Vena JE, Freudenheim JL, Dosemeci M, Michalek A Goldberg MS, Brasure J and Graham S: Risk of premenopausal breast cancer in association with occupational exposure to polycyclic aromatic hydrocarbons and benzene. Scand J Work Environ Health 25: 215-221, 1999.

82. Costantini AS, Gorini G, Consonni D, Miligi L, Giovannetti L and Quinn M: Exposure to benzene and risk of breast cancer among shoe factory workers in Italy. Tumori 95: 8-12, 2009.

83. Walker JT, Burnett CA, Lalich NR, Sestito JP and Halperin WE: Cancer mortality among laundry and dry cleaning workers. Am J Ind Med 32: 614-619, 1997.

84. Ruder AM, Ward EM and Brown DP: Mortality in dry-cleaning workers: An update. Am J Ind Med 39: 121-132, 2001.

85. Ijaz S, Verbeek J, Seidler A, Lindbohm ML, Ojajärvi A, Orsini N, Costa G and Neuvonen K: Night-shift work and breast cancer - a systematic review and meta-analysis. Scand J Work Environ Health 39: 431-447, 2013.

86. Wang P, Ren FM, Lin Y, Su FX, Jia WH, Su XF, Tang LY and Ren ZF: Night-shift work, sleep duration, daytime napping, and breast cancer risk. Sleep Med 16: 462-468, 2015.

87. Costa G, Accattoli MP, Garbarino S, Magnavita N and Roscelli F: Sleep disorders and work: Guidelines for health surveillance, risk management and prevention. Med Lav 104: 251-266, 2013 (In Italian)

88. Davis S, Mirick DK and Stevens RG: Night shift work, light at night, and risk of breast cancer. J Natl Cancer Inst 93: 1557-1562, 2001.

89. Hansen J: Increased breast cancer risk among women who work predominantly at night. Epidemiology 12: 74-77, 2001.

90. Lie JA, Roessink J and Kjaerheim K: Breast cancer and night work among Norwegian nurses. Cancer Causes Control 17: $39-44,2006$.

91. Hansen J and Lassen CF: Nested case-control study of night shift work and breast cancer risk among women in the Danish military. Occup Environ Med 69: 551-556, 2012.

92. Menegaux F, Truong T, Anger A, Cordina-Duverger E, Lamkarkach F, Arveux P, Kerbrat P, Févotte J and Guénel P: Night work and breast cancer: A population-based case-control study in France (the CECILE study). Int J Cancer 132: 924-931, 2013.

93. Li W, Ray RM, Thomas DB, Davis S, Yost M, Breslow N, Gao DL, Fitzgibbons ED, Camp JE, Wong E, et al: Shift work and breast cancer among women textile workers in Shanghai, China. Cancer Causes Control 26: 143-150, 2015.

94. Schernhammer ES, Laden F, Speizer FE, Willett WC, Hunter DJ, Kawachi I and Colditz GA: Rotating night shifts and risk of breast cancer in women participating in the nurses' health study. J Natl Cancer Inst 93: 1563-1568, 2001.

95. Åkerstedt T, Knutsson A, Narusyte J, Svedberg P, Kecklund G and Alexanderson K: Night work and breast cancer in women: A Swedish cohort study. BMJ Open 5: e008127, 2015.

96. Schwartzbaum J, Ahlbom A and Feychting M: Cohort study of cancer risk among male and female shift workers. Scand J Work Environ Health 33: 336-343, 2007

97. Pronk A, Ji BT, Shu XO, Xue S, Yang G, Li HL, Rothman N, Gao YT, Zheng W and Chow WH: Night-shift work and breast cancer risk in a cohort of Chinese women. Am J Epidemiol 171: 953-959, 2010

98. Lin X, Chen W, Wei F, Ying M, Wei W and Xie X: Night-shift work increases morbidity of breast cancer and all-cause mortality: A meta-analysis of 16 prospective cohort studies. Sleep Med 16: 1381-1387, 2015.

99. Costa G, Haus E and Stevens R: Shift work and cancer - considerations on rationale, mechanisms, and epidemiology. Scand J Work Environ Health 36: 163-179, 2010. 
100. Truong T, Liquet B, Menegaux F, Plancoulaine S, Laurent-Puig P, Mulot C, Cordina-Duverger E, Sanchez M, Arveux P, Kerbrat $\mathrm{P}$, et al: Breast cancer risk, nightwork, and circadian clock gene polymorphisms. Endocr Relat Cancer 21: 629-638, 2014.

101. Leonardi GC, Rapisarda V, Marconi A, Scalisi A, Catalano F, Proietti L, Travali S, Libra M and Fenga C: Correlation of the risk of breast cancer and disruption of the circadian rhythm (Review). Oncol Rep 28: 418-428, 2012.

102.Zhu Y, Brown HN, Zhang Y, Stevens RG and Zheng T: Period3 structural variation: A circadian biomarker associated with breast cancer in young women. Cancer Epidemiol Biomarkers Prev 14: 268-270, 2005.

103. Hoffman AE, Zheng T, Yi CH, Stevens RG, Ba Y, Zhang Y, Leaderer D, Holford T, Hansen J and Zhu Y: The core circadian gene Cryptochrome 2 influences breast cancer risk, possibly by mediating hormone signaling. Cancer Prev Res (Phila) 3: 539-548, 2010.

104.Zienolddiny S, Haugen A, Lie JA, Kjuus H, Anmarkrud KH and Kjærheim K: Analysis of polymorphisms in the circadian-related genes and breast cancer risk in Norwegian nurses working night shifts. Breast Cancer Res 15: R53, 2013.

105. Aquino NB, Sevigny MB, Sabangan J and Louie MC: The role of cadmium and nickel in estrogen receptor signaling and breast cancer: Metalloestrogens or not? J Environ Sci Health C Environ Carcinog Ecotoxicol Rev 30: 189-224, 2012.

106. Rzymski P, Tomczyk K, Rzymski P, Poniedziałek B, Opala T and Wilczak M: Impact of heavy metals on the female reproductive system. Ann Agric Environ Med 22: 259-264, 2015.
107. Byrne C, Divekar SD, Storchan GB, Parodi DA and Martin MB: Metals and breast cancer. J Mammary Gland Biol Neoplasia 18: 63-73, 2013

108. Agency for Toxic Substances and Disease Registry: Toxicological Profile for Cadmium. U.S. Department of Health and Human Services, Atlanta, GA, 2012.

109. Martin MB, Reiter R, Pham T, Avellanet YR, Camara J, Lahm M, Pentecost E, Pratap K, Gilmore BA, Divekar S, et al: Estrogen-like activity of metals in MCF-7 breast cancer cells. Endocrinology 144: 2425-2436, 2003.

110. Johnson MD, Kenney N, Stoica A, Hilakivi-Clarke L, Singh B, Chepko G, Clarke R, Sholler PF, Lirio AA, Foss C, et al: Cadmium mimics the in vivo effects of estrogen in the uterus and mammary gland. Nat Med 9: 1081-1084, 2003.

111. Cantor KP, Stewart PA, Brinton LA and Dosemeci M: Occupational exposures and female breast cancer mortality in the United States. J Occup Environ Med 37: 336-348, 1995.

112. Pollán M and Gustavsson P: High-risk occupations for breast cancer in the Swedish female working population. Am J Public Health 89: 875-881, 1999.

113. Rahim F, Jalali A and Tangestani R: Breast cancer frequency and exposure to cadmium: A meta- analysis and systematic review. Asian Pac J Cancer Prev 14: 4283-4287, 2013.

114. Romaniuk A, Lyndin M, Moskalenko R, Kuzenko Y, Gladchenko O and Lyndina Y: Pathogenetic mechanisms of heavy metals effect on proapoptotic and proliferative potential of breast cancer. Interv Med Appl Sci 7: 63-68, 2015 . 